\title{
A heterogeneidade e o pluralismo do institucionalismo: uma contribuição para o debate
}

The heterogeneity and pluralism of institutionalism:

a contribution to the debate

\section{L'hétérogénéité et le pluralisme de l'institutionnalisme: une contribution au débat}

\section{La heterogeneidad y el pluralismo del institucionalismo: una contribución al debate}

\author{
Fábio Melges ${ }^{1}$ \\ Leonardo Francisco Figueiredo Neto ${ }^{1}$ \\ Élcio Gustavo Benini ${ }^{1}$
}

Recebido em 20/02/2018; revisado e aprovado em 27/06/2018; aceito em 28/06/2018

DOI: http://dx.doi.org/10.20435/inter.v20i2.1851

\begin{abstract}
Resumo: O objetivo deste trabalho foi apontar alguns pontos de convergência e divergência entre alguns autores consagrados no campo do institucionalismo que analisaram o papel das instituições na sociedade e sua evolução ao longo do tempo. Especificamente, procura identificar como a natureza, o funcionamento e a evolução das instituições são retratados. Trata-se de uma pesquisa teórica, tendo como campo de análise a seleção de textos recorrentes no (neo) institucionalismo.
\end{abstract}

Palavras-chave: institucionalismo; instituições; desenvolvimento econômico; ambiente institucional.

Abstract: The objective of this work was to point out some aspects of convergence and divergence among some authors established in the field of institutionalism that analyzed the role of institutions in society and its evolution through time. Specifically, it aims at identifying how the nature, functioning, and evolution of institutions are portrayed. It is a theoretical research, having as a field of analysis the selection of recurrent texts in (neo) institutionalism.

Keywords: institutionalism; institutions; economic development; institutional environment.

Résumé: L'objectif de ce travail était souligner quelques points de convergence et de divergence entre certains auteurs établis dans le domaine de l'institutionnalisme qui ont analysé le rôle des institutions dans la société et son évolution dans le temps. Plus précisément, il cherche à identifier comment la nature, le fonctionnement et l'évolution des institutions sont représentés. C'est une recherche théorique, ayant comme champ d'analyse la sélection de textes récurrents dans le (neo) institutionnalisme.

Mots-clés: institutionnalisme; institutions; développement économique; environnement institutionnel.

Resumen: El objetivo de este trabajo fue apuntar algunos aspectos de convergencia y divergencia entre algunos autores consagrados en el campo del institucionalismo que analizaron el papel de las instituciones en la sociedad y su evolución a lo largo del tiempo. Específicamente, procura identificar cómo la naturaleza, el funcionamiento y la evolución de las instituciones son retratados. Se trata de una investigación teórica, teniendo como campo de análisis la selección de textos recurrentes en el (neo) institucionalismo.

Palabras clave: institucionalismo; instituciones; desarrollo económico; ambiente institucional.

\footnotetext{
${ }^{1}$ Universidade Federal de Mato Grosso do Sul (UFMS), Campo Grande, Mato Grosso do Sul, Brasil.
} 


\section{INTRODUÇÃO}

O institucionalismo se apresenta às ciências sociais como um campo de ideias não unificado. Muitas vezes, as diversas correntes que formam esse campo podem apresentar antagonismo em relação a algum tema e não reivindicam que seja formado um bloco de pensamento convergente. Williamson (2000) afirma que essa área de estudo é um caldeirão de ideias e recomenda que, enquanto não houver uma teoria institucionalista unificada, deve-se aceitar o pluralismo de seu corpo teórico.

Objetivamente é importante esclarecer que a definição do institucionalismo não é propriamente muito clara no contexto das ciências sociais. Não se pode assegurar que tal corrente de interpretação estabeleça uma escola no sentido estrito do termo, como frequentemente se faz com relação ao marxismo ou ao keynesianismo, por exemplo. Muito do que se convencionou chamar de estudos institucionais estava, na verdade, vinculado a outras matrizes de pensamento, quando não aos clássicos das ciências sociais (SILVA, 2010).

Esse campo teórico se constituiu como corrente de pensamento conhecida como Economia Institucional (EI) a partir do início do século XX, tendo como precursores Thorstein Veblen, John R. Commons e Wesley C. Mitchell. O primeiro foi o líder teórico e, ainda hoje, é autor de grande expressão e influência (LOPES, 2013). Seu trabalho se notabilizou por suas críticas sistemáticas ao neoclassicismo, principalmente às premissas desta última, baseadas em: noções de equilíbrio do sistema econômico, ao invés de mudanças; e na visão do indivíduo como sujeito autônomo e formado.

O trabalho dos autores dessa corrente, principalmente os de Veblen, colocou a El em um campo antagônico ao mainstream econômico. Dessa forma, dentro dos Estados Unidos da América, a El tornou-se a principal corrente teórica heterodoxa além do marxismo (SAMUELS, 1995), com a diferença para esta última de não propor um sistema de relações sociais alternativo ao sistema capitalista. Após a morte de seu líder, em 1929, a El perdeu força e caiu no ostracismo.

A crise dos anos 1970 abriu espaço para novas maneiras de pensar a economia. Nesse cenário, alguns estudiosos, aproveitando a lacuna ${ }^{2}$ na teoria neoclássica tradicional, incorporaram aspectos institucionais em seus estudos e formaram uma corrente teórica denominada de Nova Economia Institucional (NEI) ${ }^{3}$.

Os maiores expoentes da NEI são Douglass North, Oliver Williamson e Ronald Coase (CONCEIÇÃO, 2002; SAMUELS, 1995). O termo NEI foi cunhado por Williamson, cujo intento era diferenciar essa corrente de estudo dos "velhos" institucionalistas (COASE, 1998; LOPES, 2013; SLANGEN; LOUCKS; SLANGEN, 2008).

Assim como seus antecessores, os teóricos da NEI também criticam alguns aspectos do pensamento econômico neoclássico, como o fato de o mainstream desconsiderar a importância do papel das instituições na formação da economia.

\footnotetext{
${ }^{2}$ De acordo com Gomes (2004), North observa que há uma brecha na teoria neoclássica por esta considerar as instituições uma variável exógena de funcionamento dos mercados e, assim, incorpora essa análise à sua teoria.

${ }^{3}$ Como corrente de pensamento o institucionalismo possui grande amplitude e abrange diversas disciplinas, a exemplo da sociologia e da ciência política. De acordo com Hall e Taylor (1996), o novo institucionalismo é composto de três correntes: a) histórico; b) sociológico e; c) a do cálculo racional, que é onde se insere a NEI. No âmbito deste artigo a ênfase será dada a vertente econômica, mais especificamente a corrente estadunidense conhecida como NEI. A este respeito, Theret (2003) adverte que mesmo na corrente econômica há uma estrutura tripolar: na forma da teoria da regulação e da teoria das convenções, que surgiram na França; e, na nova economia institucional estadunidense.
} 
A crítica da El é externa e contundente ao neoclassicismo, expondo questões de distribuição de renda e poder na sociedade. As críticas da NEI têm caráter reformador, são internas ao sistema e buscam corrigir algumas falhas do pensamento econômico tradicional (LOPES, 2013).

Considerando que as diversas abordagens institucionalistas trazem importantes contribuições ${ }^{4}$ para o pensamento econômico, este trabalho procura colaborar com as discussões dessa área do conhecimento ao analisar os textos clássicos de seus principais expoentes. Dessa forma, seu objetivo foi apontar alguns pontos de convergência e divergência entre alguns autores consagrados no campo do institucionalismo econômico que analisaram o papel das instituições na sociedade e sua evolução ao longo do tempo.

Especificamente, procura identificar como a natureza, o funcionamento e a evolução das instituições são retratados. Trata-se de uma pesquisa teórica, tendo como campo de análise a seleção de textos recorrentes no institucionalismo econômico ao longo do tempo.

\section{PENSAMENTO INSTITUCIONALISTA}

Para a teoria institucionalista, a economia é um todo orgânico que está em constante movimento e transformação. As instituições são observadas sob uma perspectiva evolucionária e a economia não é um sistema simples de equilíbrio estático (VALIATI; FONSECA, 2014).

O institucionalismo é evolucionário, ou seja, enfatiza que a economia é um processo em andamento em que as instituições estão sempre se adaptando, em parte pela interação com tecnologia, leis e política. Seu tema central são as relações de poder, observando as organizações e os controles do sistema econômico ou legal, e enfatiza o conflito e não uma falsa natureza harmônica dos processos socioeconômicos. Os institucionalistas consideram que a tecnologia é a grande força de transformação de sistemas econômicos, que a atividade humana, mediada pela tecnologia, determina o que é um recurso, sua escassez relativa e sua eficiência, e que a alocação de recurso não se dá por um mecanismo de mercado abstrato, mas sim pelas estruturas de poder (instituições) que estruturam esse mercado (SAMUELS, 1995).

As origens desse campo teórico na economia surgiram nos trabalhos de Thorstein Veblen, John Commons e Wesley Mitchell, que direcionaram suas análises para a importância das instituições, mas que, entretanto, avançaram uma linha analítica mais descritiva, relegando para um segundo plano questões teóricas (CONCEIÇÃO, 2001).

Conforme Lawson (2002), o marco inicial do institucionalismo ocorreu quando, ao defender que a ciência econômica deveria reconhecer o papel da evolução das instituições em seu campo de estudo, Veblen (1898) lançou as fundações da Economia Institucional (EI).

Fundamentalmente, a abordagem vebleniana era composta de três principais pontos: i) a importância das inovações, questão negligenciada pela ortodoxia econômica neoclássica; ii) a análise de como se dá o crescimento ou mudanças econômicas ao invés da preocupação com formas estáticas, ou equilíbrios; e; iii) ênfase na transformação tecnológica e na evolução das formas econômicas (CONCEIÇÃO, 2002).

\footnotetext{
${ }^{4}$ No campo teórico institucionalista, podem ser encontradas as seguintes questões: i) a distribuição de poder na sociedade; ii) os mercados como complexos institucionais que operam com outros complexos institucionais; iii) a psicologia coletiva e a do indivíduo; iv) a formação do conhecimento ou o que é considerado conhecimento e como isso determina a alocação de recursos; v) nível e distribuição de renda; vi) a cultura geral como variável dependente e independente; e vii) que a análise de mercado constitui um coletivismo metodológico, ao contrário da defesa do individualismo metodológico defendido pelo neoclassicismo (SAMUELS, 1995).
} 
Samuels (1995) menciona que, para Veblen, o que deve ser considerado na análise da sociedade é aquilo que melhora o processo de vida, que a teoria evolucionária de valor é construída sobre hábitos e costumes da vida social.

O precursor da El destacava em sua obra como os hábitos ${ }^{5,6}$ eram a base da criação das instituições e como estas afetavam as relações sociais. Os hábitos de pensamento são a essência de suas observações, e estes são processos acumulados de gerações passadas que mediam a relação entre os indivíduos, a classe à qual pertencem e os objetos (VALIATI; FONSECA, 2014).

O autor conceitua instituições como hábitos mentais compartilhados por determinada comunidade: o consumo para ostentação, o vestuário, a linguagem, a emulação pecuniária, as regras de gosto, crenças, entre outros. Essas instituições são resultantes de um processo de seleção natural dos hábitos mais aptos que modelam, forçadamente, os indivíduos ao seu ambiente social (VEBLEN, [1899]1987).

Tais instituições influenciam fortemente práticas sociais, incluindo o consumo, portanto elas causam impactos econômicos e financeiros. Por essa razão, Veblen enfatiza que as instituições- e não o indivíduo, homo economicus - justificam as decisões econômicas e devem ser o principal objeto de estudos da economia.

Se determinado grupo está no topo da escala social, suas preferências de consumo, hábitos, maneiras de ser e costumes são imitados pelas demais classes logo abaixo na escala social. O consumo pode ser considerado uma forma de a classe dominante demonstrar superioridade pecuniária. Essa competição (emulação) na forma de consumo para ostentação, torna-se um hábito social e, por conseguinte, uma instituição, que exerce influência sobre o indivíduo para que este busque demonstrar que está apto a consumir e mostrar seu valor na escala social (VEBLEN, [1899]1987).

Portanto, para o autor, as instituições são ferramentas da classe dominante para manter seu poder em relação às demais classes sociais. O autor busca compreender o papel da instituição nas relações sociais, como elas se formam e como os atores influenciam ou são influenciados por essas instituições.

Neste contexto, o problema central dos estudos econômicos é a questão da distribuição de recursos na sociedade, ou seja, quem detêm os recursos e qual uso faz dele. Teorias que buscam demonstrar o valor dos produtos como uma simples equação de oferta e demanda e funções de equilíbrio, operando uma separação da análise da distribuição dos recursos, não podem explicar fenômenos de mudanças no cenário econômico apontando suas relações de causa e efeito (VEBLEN, 1909).

Outra vertente do trabalho do antigo institucionalista é a relação entre o papel das instituições e a tecnologia em seus trabalhos. Conforme Veblen (1904), a importância da dinâmica de negócios na estrutura social é fortemente condicionada pela fronteira tecnológica. Situados lado a lado, a perspectiva dicotômica fica mais visível. Apesar de indicar que modificações nas instituições ocorram através da continuidade do processo tecnológico, o autor não apresenta com rigor alguma explicação que evidencie como tal processo condiciona os aspectos cerimoniais envolvidos pelas instituições (BOCK; ALMEIDA, 2016).

5 “Em Veblen os hábitos surgem a partir das condições de produção vigentes em cada sociedade e são resultado de ações repetidas que condicionam a mente a pensar de determinada forma" (LOPES, 2013, p. 633).

6 "Hábito pode ser definido como uma propensão em grande parte auto atuante e não deliberativa a um padrão de comportamento previamente adotado. Um hábito é uma forma de comportamento autossustentável e não reflexivo que emerge em situações repetitivas" (HODGSON, 1998, p. 178). 
Em um contexto de desenvolvimento socioeconômico, Veblen (1904) e Faria (2001) vinculam variados tipos de relação entre e o desenvolvimento tecnológico e as formas institucionais. De acordo com os autores, um modo de desenvolvimento é resultado de um processo histórico (plano macro-histórico), decorrência de um regime de acumulação em interação com o modo de regulação (plano sistêmico) e padrão tecnológico. Ou seja, um processo que se manifesta a partir da acumulação do capital e das inovações, que influenciam e são influenciadas pela configuração das formas institucionais (plano institucional). Nessa perspectiva, a própria tecnologia é uma instituição; a base material da sociedade que transcorre do desenvolvimento técnico e científico e da sua aplicação ao modo de vida e de subsistência da sociedade.

\section{O NOVO INSTITUCIONALISMO}

Da mesma forma que o desenvolvimento do behaviorismo surgiu em oposição ao velho institucionalismo questionando sua falta de rigor metodológico, a transição do velho para o formato contemporâneo do institucionalismo é marcada por um processo de ruptura e crítica ao movimento comportamentalista (IMMERGUT, 2006). Diante da falta de cientificidade do contexto institucional da abordagem behaviorista, o neoinstitucionalismo, para Peres (2008), surge em resposta a essa limitação. Essa visão é corroborada por Easton (1969) e Dimaggio e Powel (1991).

Uma das maneiras de conceituar o novo institucionalismo é começando por aquilo que ele não é: um bloco teórico monolítico, ou seja, não é constituído de uma corrente de pensamento unificada. Há três movimentos que reivindicam para si aquele título. Segundo Hall e Taylor (1996), as diferentes correntes neoinstitucionalistas são: a histórica, a sociológica e a do cálculo racional.

Embora os autores identifiquem três correntes diferentes de pensamento, asseveram que é possível simplificar e dividir as perspectivas analíticas em duas, a saber: a perspectiva cultural e a perspectiva calculadora. Cada uma das diferentes perspectivas concentra suas análises nas instituições e de que maneira estas afetam os comportamentos dos indivíduos, tendo como premissa principal a de que as "instituições importam".

O neoinstitucionalismo sociológico utiliza o enfoque cultural, partindo da interpretação da ação baseado na dimensão cognitiva do sujeito. Por seu turno, ao que concerne ao institucionalismo da escolha racional, está presente o enfoque de cálculo, enfatizando o caráter instrumental estratégico do comportamento do agente. Dessa forma, segundo Theret (2003), os dois enfoques analisam mudanças organizacionais de maneiras opostas.

Entretanto, o institucionalismo histórico, diferentemente dos demais, apresenta uma abordagem transversal em relação às perspectivas, ou seja, reconhece que os atores agem baseado em cálculos de interesses e, ao mesmo tempo, que possuem diferentes visões de mundo. Por consequência, para Immergut (2006), os interesses são construídos politicamente e não são dados como as preferências da escolha racional.

Considerando as diferentes perspectivas, as respostas à questão de como operam as instituições na sociedade serão respondidas de maneiras diferentes. Hall e Taylor (1996) afirmam que ambas as perspectivas procuram responder a três questões fundamentais: o que as instituições fazem, quais seus mecanismos de manutenção e como atuam os atores.

Segundo a perspectiva calculadora, o papel das instituições é oferecer estabilidade ao sistema, ou seja, oferecer uma certeza quanto ao comportamento presente e futuro dos atores. Sob esta perspectiva as instituições persistem porque nelas estão "embutidas algo da ordem de um equilíbrio de Nash" (HALL; TAYLOR, 1996, p. 8). 
Já na perspectiva cultural, elas fornecem modelos morais e cognitivos aos indivíduos moldando seus comportamentos e atitudes. O indivíduo é concebido como uma entidade profundamente envolvida num mundo de instituições composto de símbolos, de cenários e de protocolos que fornecem filtros de interpretação, aplicáveis à situação ou a si próprio, a partir das quais se define uma linha de ação. As instituições não somente fornecem informações úteis de um ponto de vista estratégico como também afetam a identidade, a imagem de si e as preferências que guiam a ação (HALL; TAYLOR, 1996).

Para Thelen e Steinmo (1992), as instituições, independentemente das abordagens utilizadas, devem ser compreendidas segundo duas funções, a saber: a de agentes e de produtos da história. Elas moldam e restringem as ações dos diversos atores sociais.

Dentro do contexto da perspectiva calculadora se encontra a Nova Economia Institucional (NEI). Apesar de ser prevalecente orientada por um contexto econômico, a NEI busca combinar contribuições de diferentes disciplinas - economia, direito, administração, ciência política, sociologia e antropologia - para explicar a natureza, funcionamento e evolução de uma extensa diversidade de instituições. Para a NEl, o mais importante papel das instituições- compreendidas como as "regras do jogo", formais e informais, que "estruturam a interação social, econômica e política" - é delimitar as ações humanas. A execução desse papel pode reduzir o custo das interações entre os seres humanos, constituindo um elemento relevante à eficiência econômica e ao desenvolvimento (NORTH, 1991).

Entre os seus principais objetivos está a análise da funcionalidade econômica e propriedades de eficiência de diversos tipos de arranjos institucionais (leis, contratos, formas organizacionais), bem como das motivações econômicas que estimulam e/ou motivam processos de mudança institucional (AZEVEDO, 2000).

Samuels (1995) afirma que a NEI se desenvolveu nos EUA sem se descolar do neoclassicismo, compartilhando certas visões como a racionalidade, maximização e orientação pró-mercado, contudo, com menos formalização para questões como equilíbrio ótimo. Muitos consideram que foi Coase quem deu origem à NEI com o seu trabalho intitulado "The nature of firm", e ele próprio admite essa possibilidade (COASE, 1998).

Conforme Williamson (1988), a NEl é uma resposta aos novos desafios que surgiram diante do novo cenário institucional em que a economia, pós-crise de 1970, estava colocada. Para o autor, ela não fornece novas respostas, mas sim novas perguntas às questões tradicionais de alocação de recursos: por que certas instituições econômicas surgiram e não outras.

Para Zannella et al. (2015), a NEI abrange dois campos de pesquisa complementares: um nível de análise macro e um outro micro, ambos diretamente influenciados por Coase. O primeiro, sob a liderança de North, lida com questões como ambiente institucional: leis, normas, costumes, convenções; e o segundo, sob a influência de Williamson, lida com questões como arranjos institucionais, que trata dos mecanismos de governança das firmas.

Os tópicos mais trabalhados pelos teóricos da NEI são as organizações e as operações das corporações; a formação de sistemas de mercado e quais instituições formam esses sistemas; custos de transação; e, nos últimos trabalhos de North, o papel do poder e da ideologia na evolução dos sistemas e das instituições (SAMUELS, 1995).

A NEI em sua gênese afasta-se de Veblen e assenta seu parentesco em Commons. Williamson $(1988 ; 1991 ; 2000)$ explicitamente reconhecia a influência de velho institucionalista sobre a nova teoria, principalmente com questões ligadas aos custos de transação e a importância das instituições como mecanismos de ordem social. 
A proposição de que a unidade básica da economia que deve ser analisada é a transação foi postulada por Commons em 1934. Suas observações sobre a transação continham três princípios: conflito, mutualidade e ordem. A análise dos custos de transação e as abordagens econômicas dos estudos das organizações concentram-se na eficiência (WILLIAMSON, 1981).

Williamson (1991) segue a orientação de Commons de que a transação é a unidade básica de análise da economia. Para o autor, deve ser observada a frequência com que essa transação se repete, a incerteza das quais a transação são objeto, e o tipo e o grau de especificidade dos bens e serviços envolvidos. Outros elementos que afetam significativamente os custos de transação são a especificidade dos ativos e a frequência de realização das transações.

Custos de transação são custos ligados à necessidade de agentes se relacionarem no que diz respeito a alguma troca e da coordenação das transações realizadas entre eles. Para Coase (1937), o ponto fundamental de haver uma firma é a grande redução de contratos devido ao fato de as transações dentro dela operarem de modo organizado diferentemente do mercado. A especialização traz ganhos mediante o aprimoramento derivado da divisão do trabalho que reduz ou até mesmo elimina custos de transação (FARINA; AZEVEDO; SAES, 1997).

North (1993) resgata questões levantadas por Coase (1937) e Williamson (1991) ao demonstrar que, no ato de produzir, existem dois tipos de custos: os custos de transação e de produção. A teoria neoclássica aborda apenas os custos de produção e desconsidera o papel das instituições em sua análise. Porém, em mercados "reais", os custos de transação são significativos, e o desempenho econômico vai ser determinado pela capacidade que as instituições possuem de amenizar a incerteza e reduzir os custos de utilização dos mercados. North (2000) afirma que os atores utilizam diversas estruturas institucionais (modelos mentais, restrições) herdadas no processo decisório que têm papel fundamental na redução dos custos de transação. Dessa maneira, é necessária uma análise conjunta entre instituições (fatores extrafirma) e tecnologia (intrafirma), pois essa interação determina os custos de produção e transação e, por consequência, os custos totais.

\section{DIVERGÊNCIAS E CONVERGÊNCIAS DO INSTITUCIONALISMO}

Hodgson (1998) afirma que o institucionalismo não busca criar uma teoria de todas as coisas, mas apenas construir um quadro coerente de análise e uma metodologia viável para análise das relações socioeconômicas.

Mas, se é uma área heterogênea e com diversas abordagens, onde se encontra o ponto de divergência das suas diversas linhas de investigação?

Para Samuels (1995), o cerne da posição institucionalista é a discordância de que o mercado é o mecanismo que guia a economia. Não é o mercado que organiza e guia a sociedade, o que realmente determina a alocação dos recursos em qualquer estrutura social são as instituições, e o próprio mercado, é, em si, uma instituição (NORTH, 1977; SAMUELS, 1995).

Os institucionalistas de todas as vertentes estudam as formas de controle social e o exercício das ações coletivas e rejeitam o argumento neoclássico de puro mercado autônomo da vontade, ação e controles humanos. Os pensadores dessa teoria enfatizam os aspectos ligados à evolução social e econômica, e defendem que as instituições não são naturais, são humanas e, por isso, históricas e evolutivas (SAMUELS, 1995).

Para Veblen ([1899]1987; 1904) importa inquerir sobre as regras do jogo, quem as determina e de que forma as utiliza, o restante é incidental. Para a NEI, que toma parte de suas premissas 
do neoclassicismo, as regras estão dadas, são pré-existentes. Dessa forma, seus estudos buscam compreender como os atores se relacionam mediante essas regras estabelecidas.

Hodgson (1998) afirma que é difícil distinguir quais as diferenças entre a El e a NEI, pois não há unanimidade. Para responder a essa pergunta, ele buscou analisar o núcleo teórico dos mais proeminentes e influentes autores da El e da NEI, entre eles, Veblen, North e Williamson.

Para os economistas ligados ao mainstream, os gostos e preferências não são alvo de estudos e explicações, a economia segue com o conceito de ciência da escolha, tomando o indivíduo como algo formado, dado.

Para a NEl, essa premissa é parte de seu corpo teórico, ao contrário da antiga tradição institucionalista nos escritos de Veblen, Commons e Mitchell, até os de Myrdal e Galbraith. A noção do indivíduo como algo totalmente formado, descolado do tempo e do espaço era rejeitada pelos antigos institucionalistas. Para eles, os indivíduos interagem com as instituições ao mesmo tempo em que buscam satisfazer suas necessidades e propósitos, e estes também são moldados pelas condições socioeconômicas. O indivíduo é produto e produtor das circunstâncias (HODGSON, 1998).

Hodgson (1998) entende que a visão do sujeito para a NEl é baseada no Iluminismo. Tal premissa preconiza que o indivíduo é um ser acabado, pronto, não influenciável, racional, e, por isso, este deve ser o elemento basilar de estudo da teoria econômica, como defende o neoclassicismo. O autor argumenta que a NEI, por considerar as funções de preferência individuais como dadas, se afasta e se diferencia do antigo institucionalismo que recusava tal visão de mundo.

Depreende-se dessa afirmação, conforme pode ser observado na figura 1, que a NEI tem seu corpo teórico complementar à ortodoxia, embora faça críticas a alguns de seus fatores. Por sua vez, a El afasta-se do mainstream e situa-se no campo heterodoxo do pensamento econômico.

Figura 1- Posicionamento da El e da NEI

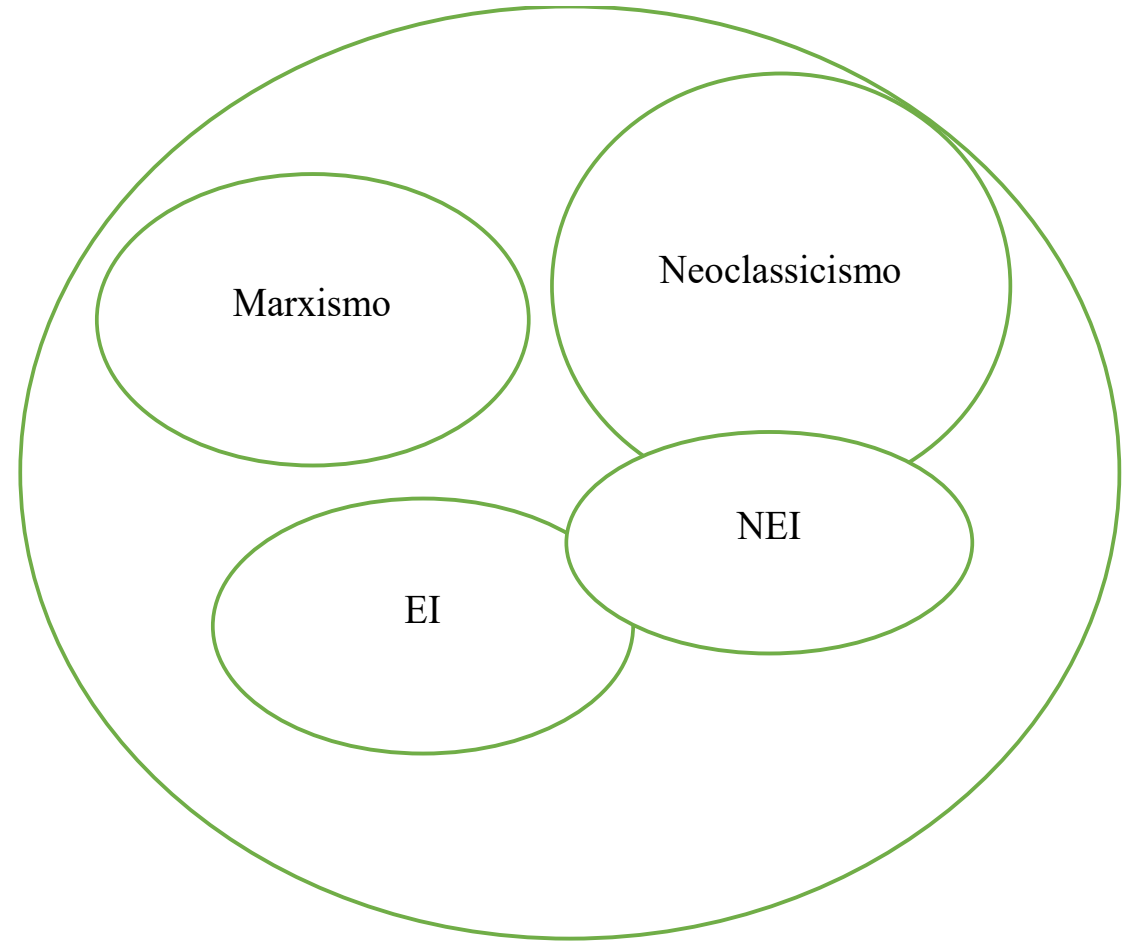

Fonte: os autores. 
Ponto central da diferença entre a El e a NEI é o conceito de hábito como moldador da vida social. O papel do hábito para a antiga tradição institucionalista era de vital importância, pois dava suporte ao comportamento do indivíduo e o provia de meios para compreensão de informações que precisam ser interpretadas e compreendidas (HODGSON, 1998).

Para a El, o indivíduo aceita, imita e compete em alguns comportamentos que se espalham como hábitos compartilhados, fazendo emergir as instituições. Estas são, portanto, ao mesmo tempo, estruturas objetivas que se apresentam e confrontam os agentes, quanto ideias subjetivas nas cabeças desses indivíduos (HODGSON, 1998).

A despeito de sua heterogeneidade, o institucionalismo, como um todo, tem como cerne a discordância de que o mercado é um mecanismo puro que guia a economia, e todas as linhas de pesquisa que compõem a grande área de estudo institucional afirmam que as instituições importam. Para todas as correntes dessa área de pensamento, o que determina a alocação dos recursos nas estruturas sociais são as instituições (Figura 2).

Figura 2- Área de convergência entre El e NEI

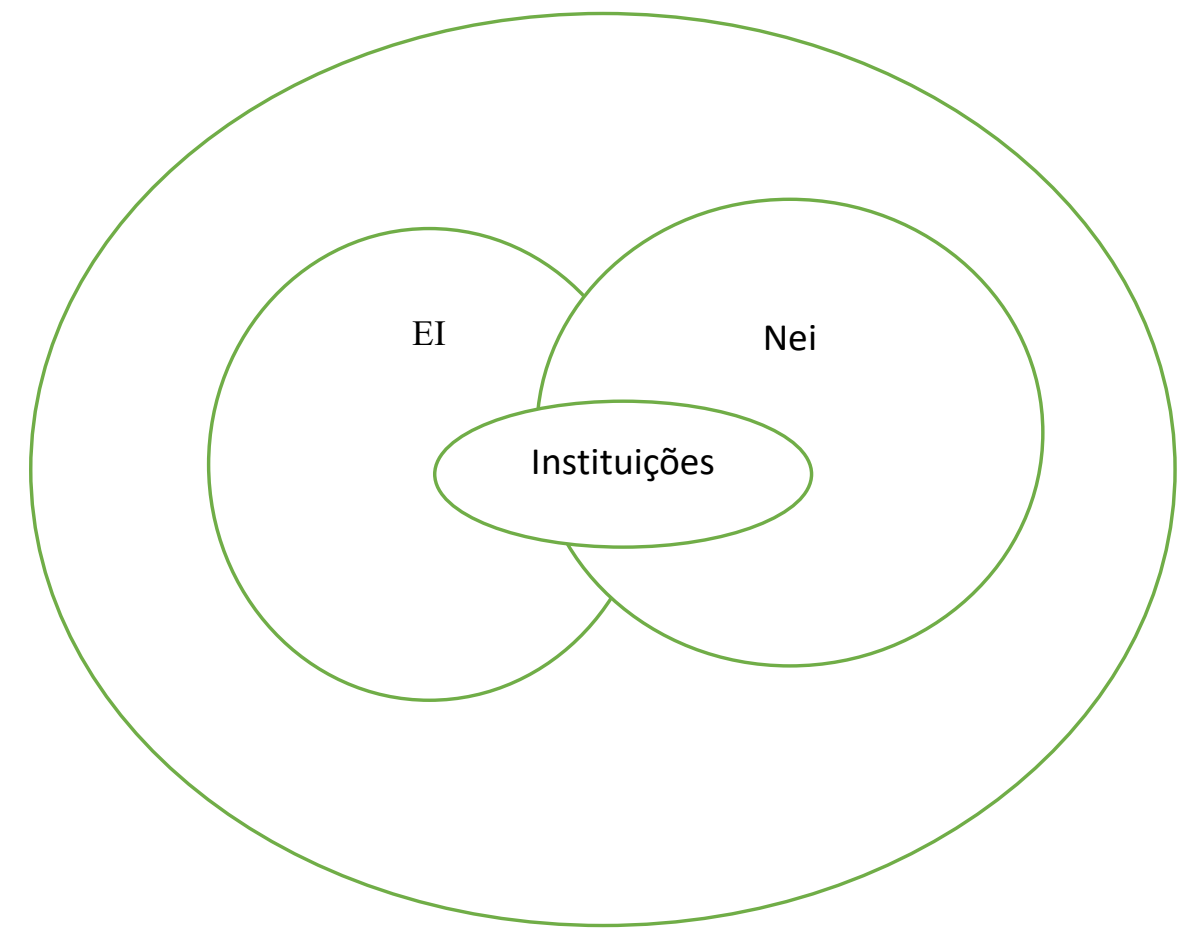

Fonte: os autores

Não obstante as divergências entre as diversas correntes que formam o campo de conhecimento institucionalista, podem ser encontradas áreas de sobreposição e convergência entre elas. O que une todas as diferentes é o reconhecimento do papel das instituições e a importância da análise de fatores históricos no processo de formação da economia.

\section{INSTITUIÇÕES - EVOLUÇÃO DO CONCEITO}

A principal unidade de análise social do campo institucionalista são as instituições. Veblen ([1899]1987) as conceituou vagamente como modelos mentais compartilhados por determinada comunidade. 
Para Hamilton (1932, p. 84) instituições "[...] são um modo de pensar ou de agir que possui certa prevalência e permanência, que está incorporada nos hábitos de um grupo ou nos costumes de um povo"7. De acordo com Commons (1931), as instituições são ação coletiva de controle, liberação e expansão da ação individual. Samuels (1995) afirma que essa visão se caracteriza como algo que cria e estrutura uma economia de livre mercado.

Hodgson (2003) afirma que o conceito de Commons está baseado em um quadro de autoridade e aparatos legais e que não considerava as auto-organizações extraoficiais, ou "orgânicas", em que as estruturas emergem sem um controle global ou uma única autoridade reguladora.

Discutindo uma possível síntese e aspectos epistemológicos do campo teórico institucionalista, Theret (2003) conceitua instituições como mediações entre as estruturas sociais e os comportamentos individuais.

Na visão de Ostrom e Ahn (2007, p. 16), "instituições são prescrições que especificam quais ações (ou resultados) são necessárias, proibidas ou permitidas e quais sanções devem ser aplicadas caso tais regras não sejam seguidas" ${ }^{8}$. As autoras ainda ressaltam que regras são resultados de esforços humanos para estabelecer a ordem.

Conforme Hodgson (2006, p. 2), "instituições são um sistema de regras sociais estabelecidas e predominantes que estruturam as interações sociais" ". Para o Hodgson (2006) instituições não são estruturas que pairam acima e separadamente do grupo de indivíduos, pois são formadas por estes e dependentes de sua interação para compartilhar hábitos mentais. Cada indivíduo nasce em um mundo institucional pré-existente que o confronta com essas regras e normas estabelecidas. À medida que os hábitos mentais vão sendo incorporados e aceitos, mais sólidas vão se tornando as bases sobre as quais se assentarão as instituições.

North (1991, p. 97) dedicou um artigo ao tema instituições conceituando-as como "restrições humanamente concebidas que estruturam a interação política, econômica e social"10. Estas podem ser formais (leis, direitos de propriedade) ou informais (tabus, sanções, costumes, tradições e códigos de conduta).

Segundo Lopes (2013), North busca evidenciar o papel das instituições no desenvolvimento econômico. Destacando que as instituições e a forma como estas evoluem representam as regras do jogo, e as empresas ou organizações são os jogadores. Essas organizações podem ser políticas, econômicas, sociais e educativas. No cenário econômico, tais organizações são tratadas normalmente como firmas, que tiram utilidade da matriz institucional (conjunto de regras formais e informais) para atingir seus objetivos. Se essa matriz incentiva os ganhos produtivos, as empresas e organizações serão fomentadoras do desenvolvimento. De outro modo, buscarão manter sua subsistência através de atividades pouco produtivas (NORTH, 1993).

\footnotetext{
${ }^{7}$ No original: "Institution is a verbal symbol which for want of a better describes a cluster of social usages. It connotes a way of thought or action of some prevalence and permanence, which is embedded in the habits of a group or the customs of a people. In ordinary speech it is another word for procedure, convention or arrangement; in the language of books it is the singular of which the mores or the folkways are the plural".

${ }^{8}$ No original: "We define institutions in broad terms as prescriptions that specify what actions (or outcomes) are required, prohibited, or permitted, and the sanctions authorized if the rules are not followed".

${ }^{9}$ No original: "we may define institutions as systems of established and prevalent social rules that structure social interactions".

${ }^{10}$ No original: "Institutions are the humanly devised constraints that structure political, economic and social interaction".
} 
Para North (1991), a necessidade de restringir a ação humana pode ser explicada por meio da teoria dos jogos, em que o indivíduo maximizador de riqueza preferirá em geral cooperar com os outros jogadores quando o jogo se repete e ele conhece o desempenho passado dos participantes. A perspectiva calculadora, tal como demonstrada por Hall e Taylor (1996), fica aqui evidenciada. Lopes (2013) reafirma, a partir do trabalho de North (1993), a influência das instituições (e, por consequência o ambiente institucional) na conduta dos indivíduos e das organizações.

Hodgson (1998) pondera que não há jogos sem regras, mas que nenhuma teoria de jogo pode por si só explicar suas próprias regras, mesmo que o jogo ocorra repetidas vezes. Para o autor, as instituições não apenas restringem, como regras, a conduta dos indivíduos, mas os influenciam, isto porque os indivíduos são parte de uma cultura e, por esse motivo, a construção das instituições não podem ser compreendidas sem levar em conta a cultura das pessoas em determinada comunidade.

Foram citados ao longo do texto conceitos de instituição elaborados por diversos autores institucionalistas. Para fins de comparação, foi elaborado o quadro 1, que traz os diversos conceitos descritos ao longo do texto:

Quadro 1- Conceitos de instituição

\begin{tabular}{|c|l|}
\hline Autor & \multicolumn{1}{|c|}{ Conceito } \\
\hline Veblen (1899) & $\begin{array}{l}\text { Hábitos mentais compartilhados por determinada comunidade: o consumo para } \\
\text { ostentação, o vestuário, a linguagem, a emulação pecuniária, as regras de gosto, } \\
\text { crenças, etc. Essas instituições são resultantes de um processo de seleção natural } \\
\text { dos hábitos mais aptos que modelam os tipos dominantes. }\end{array}$ \\
\hline Commons (1931) & Ação coletiva de controle, liberação e expansão da ação individual. \\
\hline Hamilton (1932) & $\begin{array}{l}\text { Modo de pensar ou de agir que possuem certa prevalência e permanência, que } \\
\text { está incorporada nos hábitos de um grupo ou nos costumes de um povo. }\end{array}$ \\
\hline North (1991) & $\begin{array}{l}\text { Restrições humanamente concebidas que estruturam a interação política, } \\
\text { econômica e social. }\end{array}$ \\
\hline Theret (2003) & Mediações entre as estruturas sociais e os comportamentos individuais. \\
\hline Hodgson (2006) & $\begin{array}{l}\text { Sistema de regras sociais estabelecidas e predominantes que estruturam as } \\
\text { interações sociais. Linguagem, dinheiro, leis, sistemas de pesos e medidas, } \\
\text { maneiras à mesa e as firmas (e outras organizações). }\end{array}$ \\
\hline Ostrom; Ahn (2007) & $\begin{array}{l}\text { Prescrições que especificam quais ações (ou resultados) são necessárias, } \\
\text { proibidas ou permitidas e quais sanções devem ser aplicadas caso tais regras não } \\
\text { sejam seguidas. }\end{array}$ \\
\hline
\end{tabular}

Fonte: baseado nas obras consultadas.

Conforme descrito no quadro 1, há várias definições para a palavra instituição, contudo, o termo não é necessariamente polissêmico, pois gira em torno de um núcleo relativamente fixo. De forma resumida, considerando apenas esse núcleo, pode se dizer que instituição é uma estrutura de valores e regras socialmente compartilhada que exerce o papel de interação, coerção e de vigilância sobre os indivíduos de um determinado povo.

Williamson (2000) enfatiza que devemos admitir que ainda somos muito ignorantes quanto às instituições. Hodgson (2006) lembra que as instituições são o que realmente importam no domínio social, que elas são a tessitura da vida em sociedade. O aprendizado das instituições nos faz reconhecer a importância das regras na estruturação das atividades e interação humanas. 
Reconhecendo a importância das instituições pode ser levantada a seguinte indagação: quais instituições, de fato, importam? Immergut (2006) afirma que as instituições são artefatos históricos (do processo civilizatório) que induzem a comportamentos e podem corromper ou restringir a ação humana. O autor, evocando Rousseau, destaca que as decisões políticas surgem de um conjunto de instituições que moldam os atores e que os resultados finais dessas políticas podem refletir o bem comum ou serem distorcidos.

Dessa forma, o estudo das instituições pode e deve contribuir para a construção de políticas públicas que busquem a transformação da sociedade em uma coletividade mais justa, influenciando na criação de leis que poderiam, por exemplo, reformar direitos de propriedade ou melhorar o sistema educacional.

\section{CONSIDERAÇÕES FINAIS}

O institucionalismo é um rico campo de pesquisa das ciências sociais formado por diversas linhas de pensamento. Seus estudos contemplam uma variada gama de interesses, mediante abordagem multidisciplinar, que investigam as formas de controle social, exercício das ações coletivas, crítica à organização e performance da economia.

Essa área do conhecimento explora linhas de estudo que são complementares, realizando análises micro e macro, em questões que se relacionam com normas, leis, costumes, arranjos institucionais, ambientes institucionais, mecanismos de governança das empresas, formação dos mercados, organizações e operações das corporações, custos de transação e papel da ideologia na evolução dos sistemas. Suas linhas de desenvolvimento teórico não são unificadas e, em certos momentos, possuem visões antagônicas a respeito de determinado objeto ou tema.

O antigo institucionalismo, liderado por Veblen, apresentou-se heterodoxo em relação ao pensamento econômico neoclássico. Sua preocupação central foi demonstrar como se formam as relações de poder e o papel do hábito como elemento estruturante dessas relações. Inserese, portanto, no campo da economia política, estudando as estruturas de alocação de recursos.

Para os novos institucionalistas ligados à NEl, o enfoque está em apontar falhas no pensamento ortodoxo, sem, no entanto, se contrapor totalmente a ele, utilizando as mesmas premissas deste último, com vistas ao atingimento de eficiência na alocação de recursos. A NEl objetiva a melhora do desempenho econômico e avalia a gestão dos recursos.

A El busca compreender como são formadas as regras do jogo, a quem beneficia e quais os mecanismos de manutenção dessas regras, enquanto que a NEI busca compreender como essas regras dadas são utilizadas no jogo e como os atores se movimentam para buscar a eficiência.

O institucionalismo, em suas mais variadas correntes, busca responder a três questões: o que as instituições fazem, como elas operam e qual a atuação dos atores. Embora as respostas e as abordagens sejam diferentes, de maneira geral, todas compreendem a importância das instituições nas relações sociais. Acima de tudo, o que une os diversos autores institucionalistas é a máxima que afirma que as instituições importam.

Ultrapassando essa máxima, esse campo teórico deve avançar no reconhecimento de quais instituições podem levar ao aumento do bem-estar da humanidade, à busca da justiça social e da emancipação humana. Dessa forma, o institucionalismo pode exercer protagonismo como teoria que forneça subsídios às políticas públicas redistributivas, regulatórias e constitutivas. 


\section{REFERÊNCIAS}

AZEVEDO, P. F. Nova economia institucional: referencial geral e aplicações para a agricultura. Agricultura em São Paulo, São Paulo, v. 47, n. 1, p. 33-52, jan./jun. 2000.

BOCK, R.; ALMEIDA, F. A evolução do institucionalismo vebleniano. In: ENCONTRO NACIONAL DE ECONOMIA - ANPEC, 44., 13 a 16 dez. 2016. Foz do Iguaçu. Anais [...]. Foz do Iguaçu: ANPEC, 2016. Disponível em: https://www.anpec.org.br/encontro/2016/submissao/files. Acesso em: 4 jan. 2018.

COASE, R. H. The Nature of firm. Economica, v. 4, n. 16, p. 386-405, nov. 1937. Disponível em: https:// onlinelibrary.wiley.com/doi/full/10.1111/j.1468 0335.1937. Acesso em: 14 de mar. 2017.

COASE, R. H. The new institutional economics. The American Economic Review, v. 88, n. 2, p.72-4, maio 1998.

COMMONS, J. R. Institutional economics. American Economic Review, v. 21, p. 648-57, 1931. Disponível em: https://econpapers.repec.org/article/hayhetart/commons1931.htm. Acesso em: 5 de set. 2017.

CONCEIÇÃO, O. A. C. A contribuição das abordagens institucionalistas para a constituição de uma teoria econômica das instituições. Ensaios FEE, Porto Alegre, v. 23, n. 1, p. 77-106, 2002.

CONCEIÇÃO, O. A. C. Os antigos, os novos e os neo-institucionalistas: há convergência teórica no pensamento institucionalista? Análise Econômica, Porto Alegre, v. 19, n. 36, p. 25-46, 2001.

DIMAGGIO, P.; POWELL, W. W. Introduction. In: POWELL, W. W.; DIMAGGIO, P. (Org.). The new institutionalism in organizational analysis. Chicago: University of Chicago Press, p. 1-38, 1991.

EASTON, D. The new revolution in political science. American Political Science Review, v. 63, n. 3, p. 105161, dez. 1969. Disponível em: https://www.jstor.org/stable/i333639. Acesso em: 15 fev. 2017.

FARIA, L. A. E. As formas institucionais de estrutura: do micro ao macro na teoria da regulação. Ensaios FEE, Porto Alegre, v. 22, n. 1, p. 187-204, 2001.

FARINA, M. M. Q.; AZEVEDO, P. F.; SAES, M. S. M. Competitividade: mercado, estado e organizações. São Paulo: Singular, 1997.

GOMES, F. G. A nova economia institucional (NEI) e o (sub) desenvolvimento econômico brasileiro: limites e impossibilidades de interpretação. In: SEP - ENCONTRO NACIONAL DE ECONOMIA POLÍTICA, 9., 2004. Uberlândia. Anais [...]. Uberlândia: UFU, 2004. [1 CD-ROM].

HALL, P. A.; TAYLOR, R. C. R. Political science and the three new institucionalisms. Political Studies, Oxford, v. 44, n. 5, p. 936-57, dez. 1996. Disponível em: https://onlinelibrary.wiley.com/doi/ abs/10.1111/j.1467-9248.1996. Acesso em: 5 mar. 2017.

HAMILTON, W. H. Institution. In: SELIGMAN, E. R. A.; JOHNSON, A. (Ed.). Encyclopedia of the social sciences. New York: Macmillan, v. 4, n. 73 8, p 560-95, 1932. Disponível em: https://archive.org/details/ encyclopaediaoft030467mbp. Acesso em 9 de mar. 2017.

HODGSON, G. M. John R. Commons and the foundations of institutional economics. Journal of Economic Issues, v. 37, n. 3, p. 547-76, set. 2003.

HODGSON, G. M. The approach of institutional economics. Journal of Economic Literature, v. 36, n.1, p. 166-92, mar. 1998. 
HODGSON, G. M. What are institutions? Journal of Economic Issues, v. 40, n. 1, p. 1-25, mar. 2006.

IMMERGUT, E. O núcleo teórico do novo institucionalismo. In: SARAIVA, E.; FERRAREZI, E. (Org.). Políticas Públicas. Brasília: ENAP, 2006. p. 155-95. (Coletânea, v. 1).

LAWSON, T. Should Economics Be an Evolutionary Science? Veblen's Concern and Philosophical Legacy. Journal of Economic Issues, v. 36, n. 2, p. 279-92, jun. 2002.

LOPES, H. C. Instituições e crescimento econômico: os modelos teóricos de Thorstein Veblen e Douglas North. Revista de Economia Política, São Paulo, v. 33, n. 4, p. 619-37, dez. 2013.

NORTH, D. C. Five propositions about institutional change. In: NORTH, D. C. Explaining Social Institutions. Ann Arbor: Michigan Universiy Press, 1993. p. 15-26. Disponível em: http://129.3.20.41/eps/eh/ papers/9309/9309001.pdf. Acesso em: 26 jun 2017.

NORTH, D. C. Institutions. Journal of Economic Perspectives, v. 5, n. 1, p. 97-112, 1991.

NORTH, D. C. La evolucion histórica de las formas de gobierno. Revista Economia Institucional, Bogotá, v. 2, n. 2, p. 133-48, jun. 2000. Disponível em: http://www.redalyc.org/pdf/419/41900207.pdf. Acesso em: 2 abr. 2017.

NORTH, D. C. Markets and other allocation systems in history: the challenge of Karl Polanyi. Journal of European Economic History, v. 6, n. 3, p. 703-16, 1977. Disponível em: https://dialnet.unirioja.es/servlet/ articulo?codigo=2687864. Acesso em: 15 mar. 2017.

OSTROM, E.; AHN, T. K. The meaning of Social Capital and its link to collective action, out. 2007. Disponível em: http://citeseerx.ist.psu.edu/viewdoc/download?doi=10.1.1.472.3769\&=pdf. Acesso em: 28 out. 2017.

PERES, P. S. Comportamento ou instituições? A evolução histórica do neo-institucionalismo da ciência política. Revista Brasileira de Ciências Sociais, São Paulo, v. 23, n. 68, p. 59-71, out. 2008.

SAMUELS, W. The present state of institutional economics. Cambridge Journal of Economics, v. 19, n. 4, p. 569-90, ago. 1995. Disponível em: https://academic.oup.com/cje/article-abstract/19/4/569/1687117. Acesso em: 8 fev. 2017.

SILVA, V. L. Fundamentos do institucionalismo na teoria social de Thorstein Veblen. Política e Sociedade. Florianópolis, v. 9, n. 17, p. 289-322, out. 2010.

SLANGEN, L. H. G.; LOUCKS, L. A.; SLANGEN, A. H. L. Institutional economics and economic organization theory: an integrated approach. Netherlands: Wageningen, 2008, 430 p.

THELEN, K.; STEINMO, S. Historical institutionalism in comparative politics. In: THELEN, K.; STEINMO, S.; LONGSTRETH, F. (Org.) Structuring Politics: historical institutionalism in comparative analysis. Cambridge: Cambridge University Press, 1992. Disponível em: http://www.sidalc.net/cgi-bin/wxis.exe. Acesso em: 7 mar. 2017.

THERET, B. As instituições entre as estruturas e as ações. Lua Nova, São Paulo, n. 58, p. 225-54, 2003.

VALIATI, L.; FONSECA, P. C. Institutions and culture: Thorstein Veblen's and Pierre Bordieu's economic thought in dialogue. Iberian Journal of the History of Economic Thought, v. 1, n. 1, 1-17, 2014.

VEBLEN, T. A teoria da classe ociosa: um estudo econômico das instituições. São Paulo: Abril Cultural, 1987. 181p. [1a edição em inglês, 1899]. 
VEBLEN, T. The limitations of marginal utility. Journal of Political Economy, v. 17, n. 9, 1909. Disponível em: http://www.jstor.org/stable/10.2307/1822146. Acesso em: 5 jan. 2017.

VEBLEN, T. The theory of business enterprise. New York: Charles Scribner's Sons, 1904. Disponível em: https://www.taylorfrancis.com/books/978135130247. Acesso em: 22 fev. 2017.

VEBLEN, T. Why is economics not an evolutionary science? The Quarterly Journal of Economics, v. 12, n. 4, p. 373-97, 1898. Disponível em: https://academic.oup.com/qje/article-abstract/12/4/373/1918632. Acesso em: 10 mar. 2017.

WILLIAMSON, O. E. The new institutional economics: taking stock, looking ahead. Journal of Economic Literature, v. 38, n. 3, p. 595-613, feb. 2000. Disponível em: https://pdfs.semanticscholar.org/abca/15e9 c26e155ccf2313d1b8504a7afe7fa9a8.pdf. Acesso em: 15 dez. 2016.

WILLIAMSON, O. E. Comparative economic organization: the analysis of discrete structural alternatives. Administrative Science Quarterly, v. 36, n. 2, p. 269-96, jun. 1991. https://www.jstor.org/stable/2393356. Acesso em: 15 dez. 2016.

WILLIAMSON, O. E. Corporate governance and corporate finance. Journal of Finance, v. 43, n. 3, p. 567-91, jul. 1988. Disponível em: https://www.jstor.org/stable/i340139. Acesso em: 15 dez. 2016.

WILLIAMSON, O. E. The economics of organization: the transaction cost approach. American Journal of Sociology, v. 87, n. 3, p. 548-77, nov. 1981. Disponível em: https://doi.org/10.1086/227496. Acesso em: 15 dez. 2016.

ZANELLA, C.; GONÇALVES LOPES, D.; SILVA LEITE, A. L.; NUNES, N. A. Conhecendo o campo da economia dos custos de transação: uma análise epistemológica a partir dos trabalhos de Oliver Williamson. Revista de Ciências da Administração, Florianópolis, v. 17, n. 42, p. 64-77, ago. 2015.

\section{Sobre os autores:}

Fábio Melges: Mestrando no curso de Administração da Universidade Federal do Mato Grosso do Sul (UFMS). E-mail: fabiobmelges@gmail.com, Orcid: http://orcid.org/0000-0001-8914-9925

Leonardo Francisco Figueiredo Neto: Doutorado em Engenharia (Engenharia de Produção) pela Universidade de São Paulo Engenheiro. Mestrado em Ciências (Economia Aplicada) pela Universidade de São Paulo. Especialização em Administração Rural pela Universidade Federal de Viçosa, e em Gestão Agroindustrial pela Universidade Federal de São Carlos. Agrônomo pela Universidade Federal do Espírito Santo. Professor associado da Universidade Federal de Mato Grosso do Sul. E-mail: Iffneto@gmail.com, Orcid: http://orcid.org/0000-0002-4456-3396

Élcio Gustavo Benini: Professor do Programas de Pós-graduação em Administração (PPGAD) da Universidade Federal de Mato Grosso do Sul. Doutor em Educação pela Universidade Federal de Mato Grosso do Sul. Pesquisador do grupo de Estudos e Pesquisa em Organizações, Trabalho e Educação (GEPOTE/CNPq).E-mail: elciobenini@yahoo.com.br, Orcid: http://orcid.org/0000-0002-0949-3062 
